\title{
LA VARIA FORTUNA DEL CONDESTABLE: UNA IMAGEN ROMÁNTICA DE DON ÁLVARO DE LUNA
}

\author{
Salvador García Castañeda \\ The Ohio State University
}

\section{RESUMEN}

Don Álvaro de Luna (1388?-1453) alcanzó un poder nunca visto, y los nobles, que le veían con temor y con envidia, le acusaron de tener dominado al débil e indeciso monarca Juan II, quien muy a su pesar le condenó a muerte. Las circunstancias de su ejecución y el valor y la dignidad con que don Álvaro fue al patíbulo atrajo a los autores y artistas románticos, que vieron en él una víctima del sino y de los altibajos de la fortuna. Estudio aquí cuatro obras consideradas representativas: un relato breve, «The Fate of Luna» de Telesforo de Trueba y Cosío; el romance histórico «Don Álvaro de Luna» del Duque de Rivas; el drama histórico, Don Álvaro de Luna de Antonio Gil y Zárate; y un romance de ciego, El Suplicio de D. Álvaro de Luna, de «F. M».

Palabras Clave: Álvaro de Luna, Juan in, Telesforo de Trueba y Cosío, duque de Rivas, Antonio Gil y Zárate, Romanticismo, muerte.

\section{Abstract}

Don Álvaro de Luna (1388?-1453) became the most powerful statesman of his time, but the nobility jealous and fearful of his power- pressured King Juan II of Castile, a weak and ungrateful man, to sign his death sentence. The circumstances of his execution, and the courage and poise in meeting his death at the scaffold sparked the imagination of Romantic authors and artists, who considered him a victim of Destiny and of capricious Fortune. In this article, I study four representative works of that period: Telesforo de Trueba y Cosío's short story «The Fate of Luna»; the Duque de Rivas's historical romance «Don Álvaro de Luna»; the historical drama Don Álvaro de Luna by Antonio Gil y Zárate; and «F. M.»'s El Suplicio de D. Álvaro de Luna, a «romance de ciego».

KEY WORDS: Álvaro de Luna, Juan II, Telesforo de Trueba y Cosío, Duque de Rivas, Antonio Gil y Zárate, Romanticism, death.

Don Álvaro de Luna (Cañete, entre 1388 y 1390-Valladolid, 2 de junio de 1453),

Recibido: 30-06-2017 / Aceptado: 17-07-2017 
pertenecía a una ilustre familia partidaria de la casa de Trastámara y fue el favorito del rey Juan II de Castilla (Toro, 6 de marzo de 1405-Valladolid, 22 de julio de 1454), quien reinó en tiempos de constantes revueltas e intrigas. Fue condestable de Castilla y maestre de Santiago, entre otros títulos, alcanzó un poder nunca visto y los nobles, que le veían con temor y con envidia, le acusaron de tener dominado al débil e indeciso monarca, de acumular poder y riquezas y de deshacerse sin piedad de sus enemigos. Su influencia duró largos años y, aunque en más de una ocasión perdió el favor real, lo recuperó en breve. Defendió a Juan II de quienes pretendían dominarle y gobernó sabiamente y con firmeza. Al cabo, la segunda esposa del rey, doña Isabel de Portugal, celosa de su poder, y aliada con la nobleza, consiguió indisponerle contra su favorito, quien acusado de traición y de vagos crímenes contra el Estado fue ejecutado públicamente en la Plaza Mayor de Valladolid el 2 de junio de 1453 y murió cristianamente, digno y sereno, ante la admiración y la compasión de las gentes. El rey le sobrevivió poco más de un año y acabó, al parecer abrumado por los remordimientos, el 21 de julio de 1454 .

Los biógrafos han dejado contradictorias semblanzas de don Álvaro de Luna, que reflejan sus simpatías políticas. Destacó entre sus contemporáneos, y sobre todo sobre el mismo rey, por su inteligencia y su firmeza y, al igual que don Pedro i de Castilla, «Cruel» para unos, y para otros «Justiciero», atrajo a quienes vieron en su triste sino el de un ser de excepción derribado por la caprichosa rueda de la Fortuna.

He escogido aquí cuatro obras que considero representativas de la imagen del condestable que dio el Romanticismo: un relato breve, "The Fate of Luna», en The Romance of History. Spain, de Telesforo de Trueba y Cosío, cuyo Prefacio está firmado en 1829 y vio la luz en 1830; el romance histórico «Don Álvaro de Luna» (1833) del duque de Rivas; el drama histórico Don Álvaro de Luna (1840) de Antonio Gil y Zárate; $\mathrm{y}$, en un género propio de la literatura de cordel, el romance de ciego El Suplicio de D. Álvaro de Luna, (1872) de «F. M.» cuya fecha mostraría la pervivencia de la popularidad del personaje en época tan tardía.

Edward Bull, propietario de la New Subscription Library, de Londres, publicó la serie Romance of History, cuidadosamente editada, que por su asunto podría interesar al público lector inglés. Salieron tres volúmenes en $8^{\text {vo }}$, England, Italy y Spain y, según The Morning Chronicle, la serie era apropiada para regalos de Navidad y Año Nuevo. The Romance of History. Spain (1830) es una colección de cuadros representativos de la historia de España contados de forma breve y amena.

En «The Fate of Luna» Telesforo de Trueba y Cosío trata de las ultimas maquinaciones de Isabel de Portugal y de los nobles contra don Álvaro de Luna, de la indecisión del pusilánime Juan in y de la gran presencia de ánimo y la dignidad con las 
que don Álvaro recibió la muerte.

Trueba escribió novelas históricas y conocía bien la vida del condestable, pero no dudó en mezclar la leyenda y la historia tanto en este relato como en otros, pues escribía en inglés para un público en su mayoría desconocedor de España al que, en The Romance of History, se daba una versión simplista de su historia.

La narración comienza cronológicamente poco antes de la caída de don Álvaro y relata la culminación de la conjura para lograr su muerte. Aunque Isabel de Portugal le debía su matrimonio, determinó deshacerse de él para tener influencia absoluta sobre su esposo. Juan ir habría querido casarse con la princesa francesa Fredegonda pero no lo hizo, influido por Luna, y la princesa, resentida, se unió a sus enemigos. Entre ellos, el joven Zúñiga, sobrino del poderoso conde de Valencia; «La belleza, la compasión, el amor y otras consideraciones hicieron a Fredegonda objeto del apasionado amor del joven Zúñiga» ${ }^{1}$ quien, para complacerla, levantó un ejército y llegó a Burgos para liberar al rey y al pueblo del dominio de don Álvaro.

Este trató desdeñosamente los manejos de sus enemigos. Diego Gotor, su fiel criado, y el paje Morales le urgieron a huir disfrazado pero se negó a hacerlo por no ser propio de caballeros, perdió un tiempo precioso y se retiró a dormir. A las cinco de la mañana las tropas de Zúñiga rodearon su casa. Trueba describe ahora en detalle las circunstancias históricas de los últimos días del condestable, cómo su presencia en la ventana fue recibida con hostilidad e insultos, cómo entregó su espada a Zúñiga y quedó preso en una habitación con guardias de vista. Y destaca la alegría de los conjurados, que manifestaron con bandas de música por las calles, con el populacho que gritaba insultos, con toque de campanas y una misa en acción de gracias celebrada por el obispo de Ávila, a la que asistió el rey. La comitiva pasó bajo las ventanas de Luna pero el rey no se atrevió a levantar la vista.

Todavía confiaba en su poder y, al cabo de tres días, pidió al rey una entrevista, quien se la negó, atemorizado por la reina; don Álvaro escribió entonces una carta al rey en la que le recordaba sus servicios, pero un tribunal formado por sus enemigos le acusó sin datos concretos de haber usurpado la autoridad real, y le condenó a muerte. Y Juan II, «aquel hombre débil e ingrato, con la frivolidad y veleidad de una mente débil y de una disposición indolente ${ }^{2}$, olvidando los beneficios que debía al de Luna,

\footnotetext{
1 «Beauty, pity, love, and a variety of considerations, rendered the Princess an object of absorbing interest in the estimation of young Zúñiga». (T. de Trueba y Cosío, «The Fate of Luna», The Romance of History. Spain. With Illustrations by J. K. Meadows, The Chandon Classics, London, Frederick Warne and Co., 1872, pp. 401-425. $1^{\mathrm{a}}$ ed.: The Romance of History. Spain, III, Londres, Edward Bull, propietario de la New Subscription Library, 1830.

${ }^{2}$ «This feeble and ungrateful man wanted no longer any very powerful stimulus to make [...] With the
} 
firmó su sentencia.

En medio de la expectación general se alzó el cadalso en la Plaza Mayor de Valladolid, cubierto con un rico paño negro, y con un gran crucifijo. Don Álvaro pasó la mañana con su confesor, comulgó y se le leyó la sentencia, que oyó «con la fortaleza viril y elevación de pensamiento tan propias de su carácter» ${ }^{3}$. Rezó brevemente y dijo con voz serena: «Vamos al patíbulo. Estoy dispuesto» ${ }^{4}$. Trueba describe el paso de Luna por las calles, con expresión digna y tranquila, y de sus servidores, vestidos de negro, rodeados por la tropa, el son de los tambores destemplados y el cambio en la actitud de la inmensa multitud, ahora dolorida y piadosa. Subió firme al patíbulo y, dirigiéndose a uno de los partidarios de don Enrique el infante de Aragón, le dijo: «Di a tu amo que premie los servicios de sus fieles criados de otro modo que lo hace el rey de Castilla» ${ }^{5}$. Y al ver al paje Morales, el único que le había sido fiel hasta el final, se quitó el sombrero y un anillo de oro y se los dio: «Recíbelos, mi joven amigo, como triste recuerdo de tu desdichado señor» ${ }^{6}$. Comenta Trueba que el paje se echó a llorar y que lo mismo hizo la multitud, y aquel testimonio de simpatía popular endulzó los últimos momentos del condestable: «una melancólica sonrisa se dibujó en sus labios, y puso una mano sobre su corazón para agradecer aquel testimonio de sentimiento por su destino» ${ }^{7}$. Miró el garfio del que iba a colgar su cabeza y sacó del seno una cinta negra, la besó y se la dio al verdugo para que con ella le atara las manos. Después oró fervorosamente unos momentos y con resolución y compostura puso la cabeza sobre el tajo; el verdugo se la cortó de un hachazo y la mostró a un público horrorizado y afligido.

Quedó expuesta algún tiempo, pero hubo de retirarse ante las protestas de la gente. Los restos del grande, del poderoso, del magnánimo don Álvaro de Luna fueron enterrados de caridad en la parte del cementerio destinada a los asesinos y a los malhechores. Y Trueba considera que las dos cosas más precarias son la gratitud de un rey débil y el aprecio de las masas, y que nadie fue capaz en Castilla de llenar el vacío que dejó aquel hombre, víctima de los celos y de la envidia.

levity and fickleness natural to a weak intellect and an indolent disposition». (Ibidem, p. 19).

${ }^{3}$ «[...] with that manly fortitude and elevation of mind which so strongly marked his character». (Ibidem, p. 40).

${ }^{4}$ «Lead on to the scaffold. I am ready». (Ibidem, p. 42).

5 «Tell thy master to reward the services of his faithful servants in a different manner to the King of Castile». (Ibidem, p. 43).

${ }^{6}$ «Receive this, my young friend, and keep them in mournful remembrance of thy unfortunate master». (Ibidem, p. 44).

${ }^{7}$ «A melancholy smile played on his proud lips, and he placed his hand fervently on his heart, in token of his acknowledgements for the popular sensation in his fate». (Ibidem, pp. 44-45). 
Al igual que a otros autores de su tiempo atrajeron a Telesforo de Trueba los personajes heroicos, como el Cid y Guzmán el Bueno, o los notorios por sus excesos y por sus vicios, como el rey don Pedro, a quien dedicó la novela The Castilian, el drama The Royal Delinquent y dos narraciones en The Romance of History. En esta última serie hubo de limitarse a cierto número de páginas por lo que apenas hallamos la moralización y las digresiones a las que fue tan aficionado. Cuenta en tercera persona e introduce diálogos, a veces extensos, que dan vida a los personajes, diálogos que en ocasiones reproducen o glosan otros tenidos por históricos, o que son hijos de su fantasía. Y como en las demás narraciones de este libro, «The Fate of Luna» va precedido de un breve «Historical Summary» que contribuye al entendimiento de los reinados de Juan II y Enrique IV.

En sus Romances históricos escoge el duque de Rivas aquellos episodios y figuras del pasado que le parecen más representativos del espíritu nacional; ya siga la historia, ya la invente, y al igual que hizo antes Trueba, pinta a sus antepasados como capitanes heroicos, justicieros monarcas y hombres de temple que encarnan cualidades atribuidas a los españoles rancios. Y tanto para el autor de Don Álvaro como para sus contemporáneos, la evocación de las glorias patrias y el poetizar la España castiza es siempre más importante que la realidad del hecho histórico.

Los protagonistas de sus Romances no son del mismo linaje que los del romancero tradicional. Aquellos eran héroes y los creados por él, lo sean o no, se distinguen por el aura que rodea a los seres de excepción; Rivas no retrata a sus personajes en la plenitud de su gloria, sino en batalla, serenos ante la muerte, siempre en momentos cruciales en los que revelan su hombría y su temple moral.

«Don Alvar de Luna» aparece brevemente en la octava XIX de su poema El paso honroso de 1820-1821, junto a Juan II, el «excelso monarca, aficionado/ a tanto amor y tanta gallardía» ${ }^{8}$, y bastantes años más tarde le dedicará un romance. «Don Álvaro de Luna» está fechado por la edición de 1854 en «París, 1833»; tiene 592 versos, distribuidos en cuatro romances en cuartetas: el I con 180 versos con rima asonantada en é-o; el II, 140 en í-o; el III, 184 en ú-a; y el IV, 160 en é-a. Rivas estructuró sus romances como novelas históricas o como dramas; cada uno de ellos se divide en varias partes, a modo de capítulos o de actos, y suelen llevar un título, y estos últimos, a su vez, lo están en otras partes menores que corresponderían a las diferentes escenas de una obra teatral.

Al igual que en el drama Don Álvaro y en otros romances, las escenas

\footnotetext{
${ }_{8}^{8}$ Á. de Saavedra, El paso honroso, Obras completas, I, Poesías, Jorge Campos (ed.), Madrid, Biblioteca de Autores Españoles, 1957, pp. 66-94.
} 
costumbristas dotadas de cierta comicidad alternan con las de carácter histórico y dramático. El romance inicial, «La venta», que sirve de introducción, es un pintoresco cuadro de costumbres en el que el ventero y su mujer mantienen una agitada y cómica discusión sobre la situación del condestable; son gente humilde cuyas encontradas opiniones representarían las de las clases populares de entonces. El padre Espina y otro franciscano toman allí unas «magras con tomate y huevos», y a poco, «sobre sus mulas subieron, / y aquella venta dejaron / hecha un abreviado infierno» ${ }^{9}$. Esperan en el camino a una tropa a caballo, mandada por don Álvaro de Estúñiga, que rodea a un preso, «Don Álvaro era de Luna, / del rey don Juan favorito, / que a Castilla largos años/ rigió sin freno a su arbitrio» ${ }^{10}$. Se agregan a la comitiva y el fraile, cautamente y con gran tacto va dejándole entrever el verdadero fin de este viaje.

¿Voy a morir acaso?

[...] Todos; mientras somos vivos, vamos a morir. El hombre que va preso... en más peligro... ${ }^{11}$

La conversación hasta la llegada a Valladolid seguiría de cerca el relato del supuesto Ciudarreal y, quizá, el texto del «Don Álvaro de Luna» de Quintana ${ }^{12}$, y Rivas añade que Estúñiga y los soldados lloran dentro de la celada. Al llegar a Valladolid, «entre dos luces», pasan delante de la casa de Alonso López Vivero, a quien Luna había hecho asesinar; cree ver su espectro ahora y por la noche confiesa su crimen al fraile. Para no hacer la relación prolija, Rivas enumera las ocupaciones de su última noche:

Cenó, durmió cortos ratos, repitió también algunas trovas del famoso Mena

\footnotetext{
${ }^{9}$ Á. de Saavedra, «Don Álvaro de Luna», en S. García Castañeda (ed.), Romances históricos, Madrid, Cátedra, 1987, p. 157.

${ }^{10}$ Ibidem, p. 160.

${ }^{11}$ Ibidem, p. 161.

${ }^{12}$ «Nadie tuvo ánimo para decirle adonde le llevaban; pero al camino salieron como por acaso dos frailes franciscanos del convento del Abrojo; uno de ellos fray Alonso de Espina, célebre teólogo y predicador entonces y conocido de don Álvaro. Trabó conversación con él y se puso a caminar en compañía suya, tratando de moralidades en general sobre los desengaños que da el mundo, y caprichos y reveses de la fortuna. Azorose él con esta plática, y creyéndola preámbulo de otra más grave y funesta, preguntó al religioso si iba acaso a morir. «Todos mientras vivimos caminamos a la muerte, pero el hombre preso está más cercano a ella, y vos, señor, estáis sentenciado ya». Entonces el maestre, reponiéndose de su turbación primera, "Mientras un hombre ignora, replicó, si ha de morir, o no, puede recelar y temer la muerte; pero luego que está cierto de ello, no es la muerte tan espantosa a un cristiano, que la repugne y rehúse, y pronto estoy a ella si es la voluntad del rey que muera". El resto de la conversación fue consiguiente a este principio; rogó al padre Espina que no le desamparase en aquel trance, y así hablándole y consolándole llegaron a Valladolid» (M. J. Quintana, «Don Álvaro de Luna», en Vidas de españoles célebres, Madrid, Biblioteca de Autores Españoles, XIX, Imprenta y Estereotipia de M. Rivadeneyra, 1852, pp. 367-431 y pp. 502-504).
} 
que pintan como locuras

las mundanas ambiciones;

oró con fervor, en suma

fue un cristiano, un caballero,

un hombre de fe y de alcurnia ${ }^{13}$.

En cambio, el rey llora angustiado,

Revolcándose en su lecho,

rasgando sus vestiduras,

paseándose sin tino,

por la cámara, que alumbra

una lámpara medrosa,

que en el cortinaje abulta

vagas sombras... $[\ldots]^{14}$.

Pero la reina entra «cual una / aparición, como maga / que viene a doblar astuta/ los encantos y conjuros», y el rey «quedó de mármol / al verla». «¿Qué es esto?» «Nada» ${ }^{15}$. «Y el trono, cetro y corona/maldiciendo en voces mudas, /ojos de lágrimas llenos/ clavó en la menguante luna» ${ }^{16}$.

También el último romance (IV, «La plaza»), podría seguir de cerca a Quintana. Rivas describe sobriamente el paso de don Álvaro por las calles, «con tan gallarda presencia / y con tan sereno rostro, /que impone a cuantos le encuentran ${ }^{17}$. La voz del pregonero rompe «aquel silencio terrible» ${ }^{18}$. Sobre el reducido tablado están el condestable sereno, que regala al paje Morales un anillo de oro, el tosco verdugo, al que da «una cinta / labrada con oro y seda» ${ }^{19}$ para que le ate los pulgares, y el religioso «de mármol» ${ }^{20}$, que reza.

$\mathrm{Y}$ en medio, de firme, un tajo delante una almohada negra, y un hacha en cuya cuchilla los rayos del sol reflejan» ${ }^{21}$.

Contrariamente a otros autores, Rivas da fin a su relato con la ejecución del maestre; acertadamente sustituye el puñal de la Crónica por un hacha, más efectista y

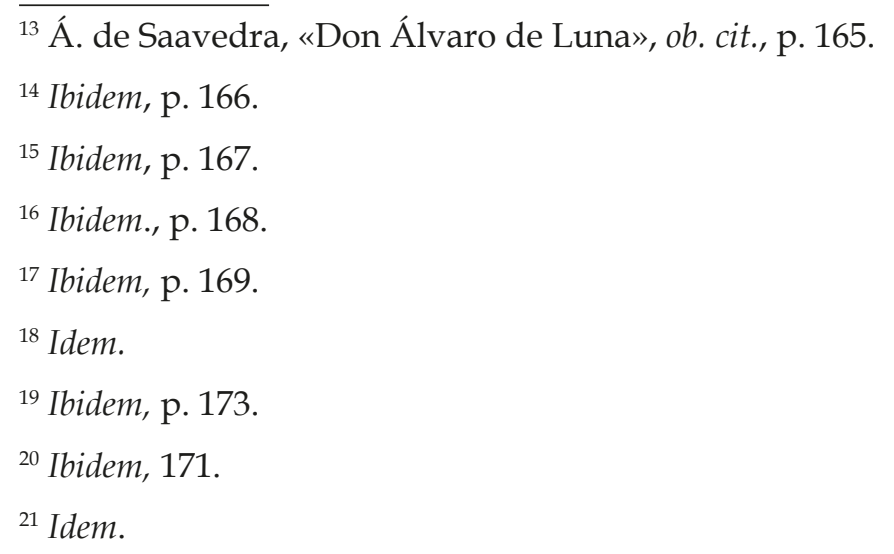


más noble, y concluye con elegante sobriedad de modo conciso y rotundo.

El hacha cae como un rayo,

Salta la insigne cabeza,

Se alza universal gemido,

Y tres campanadas suenan ${ }^{22}$.

Acertadamente usó de aquellos recursos propios de las leyendas y de los cuentos populares que dan visos de autenticidad a lo narrado, como la evocación de lugares que fueron testigos de viejas historias o morada antaño de gentes que son hoy olvidados fantasmas, y en este romance la de las ruinas de aquella pretendida venta en el camino a Valladolid.

Como se recordará, en sus tiempos de exilio, Ángel Saavedra en más de una ocasión se ganó la vida pintando; y su obra escrita despliega una magistral creación de ambientes conseguida con un vocabulario evocador y colorista, y un uso de la luz y de la sombra, como en «Una antigualla de Sevilla» o en «El cuento de un veterano», con el que alcanza matices propios del tenebrismo de la novela gótica.

La situación atmosférica corresponde al estado anímico de los personajes (recuérdese el final de Don Álvaro). Y al declinar la tarde a la par que la vida del maestre, pinta un cuadro

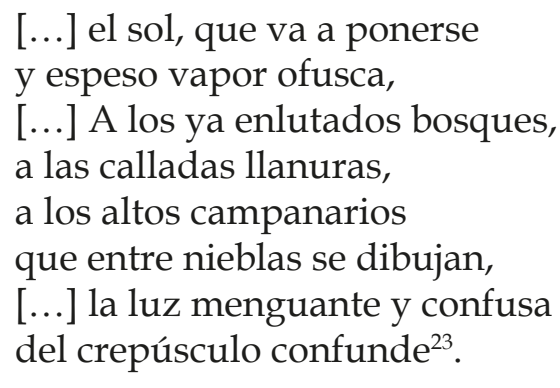

en el que dominan el claroscuro y la melancolía de un impreciso paisaje difuminado.

Destacan sus retratos de personajes, y sus descripciones de grupos de los que son buena muestra el del condestable y el colorista de Estúñiga:

En un alazán fogoso, viene, de hierro vestido, la gruesa lanza en la cuja, la luenga espada en el cinto, un penacho jalde y negro, cual matorral sobre un risco, ondea sobre su almete,

\footnotetext{
${ }^{22}$ Ibidem, p. 173.

${ }^{23}$ Ibidem, pp. 162-163.
} 
y da al sol variados visos ${ }^{24}$.

El condestable pasa por el romance como una imagen de resignado infortunio. Cada vez más cercano su fin, crece en dignidad y estatura moral mostrándose superior a cuantos le rodean y al mismo rey — «iGrande mal es la flaqueza / en hombre que cetro empuña! ${ }^{25}$-, víctima de su falta de ánimo y de su impotencia. En las poesías que escribió Ángel Saavedra antes de ir al destierro está ya presente su tendencia a moralizar y en estos romances destaca lo inestable de nuestro estado, la temporalidad de las cosas, la pérdida de la juventud, la brevedad del poder y de la belleza, y los caprichos de la fortuna. El condestable no es más que un instrumento en manos de la Providencia, cuyos designios ignora.

El Suplicio de D. Álvaro de Luna (1453) es un romance del género de los llamados «de ciego» firmado por «F. M.» Tiene 272 versos, en dos partes, la I con 112 versos y la II con 160. El autor conoce bien sus fuentes, no se aparta de los hechos históricos y firma con sus iniciales, pero el romance tiene la monotonía de una narración de 272 versos en los que no cambia la asonancia en -a, y un tono narrativo carente de color, de lirismo y de emoción. Aunque ha evitado caer en algunas fórmulas propias de este tipo de composiciones, como son la invocación inicial a la Virgen o a los santos, y el final didáctico-moral, hay otras enfáticamente melodramáticas —«Don Enrique, / víbora de estirpe regia; [...] Pero la envidia no puede/ herir la altiva cabeza,/ pues nació para arrastrarse/ por el cieno de la tierra. ${ }^{26}-\mathrm{y}$ de consideraciones morales

Ya ha llegado la mañana que todo en el mundo llega, atropellando a la dicha el torrente de las penas.

$[\ldots]$

¡Cuán liviana y deleznable es la terrenal grandeza!

Ayer astro refulgente, ni sombra suya hoy siquiera ${ }^{27}$.

tan propias de este tipo de romances. Contrariamente a otros pliegos de cordel que aprovechan viejas ilustraciones, la xilografía que encabeza el texto se grabó expresamente para esta narración, y tiene bastante calidad.

\footnotetext{
${ }^{24}$ Ibidem, p. 158.

${ }^{25}$ Ibidem, p. 166.

${ }^{26}$ F. M., El Suplicio de D. Álvaro de Luna (1453), número 340, Madrid, Depósito Central, Librería de la Viuda e hijos de D. J. Cuesta, Imp. de J. Noguera a cargo de M. Martínez, 1872. El romance consta de cuatro páginas no numeradas; la paginación a la que remitimos es nuestra. Aquí, p. 2.

${ }^{27}$ Ibidem, pp. 2-3.
} 
El romance i comienza contando la situación política del país durante el reinado de Juan II: «Revuelta andaba Castilla...» y hace un retrato del rey, «que siendo el segundo / fue el postrer en toda empresa ${ }^{28}$. Los infantes de Aragón y los nobles pretenden dominar a «aquel rey siervo de todos / si por don Alvar no fuera» ${ }^{29}$. quien es aquí un personaje noble y leal combatido por las asechanzas y la envidia. El rey firma su sentencia, y «a Valladolid va preso / donde el verdugo le espera» ${ }^{30}$. El romance II, más largo que el primero, se centra en el día en el que marcha sereno desde la prisión -reina un «sepulcral silencio/ llanto y congoja doquiera» ${ }^{31}$ - hasta su muerte en el cadalso.

«F. M.» es un autor omnisciente que narra en tercera persona - «en su frente serena/ late un mundo de recuerdos/ y una tempestad de penas» ${ }^{2}-$ que parece conocer bien alguna versión anterior del asunto de su romance pues se refiere a «los laureles de Higueruela» ${ }^{33}$, evoca el asesinato de Alonso Pérez de Vivero - «el fantasma de Vivero / ni le oprime ni le arredra ${ }^{34}-\mathrm{y}$ menciona al criado Barrasa y al Padre Espina. Poco antes de morir da un anillo y el sombrero que llevaba puesto a su paje Morales:

Este es don Alvar de Luna, el primero en la pelea, tan brioso en el torneo como galán en las fiestas [...] víctima de la injusticia ${ }^{35}$.

De todas estas versiones, la más alejada de la historia es la del drama en cinco actos Don Álvaro de Luna, de Antonio Gil y Zárate, centrado en las conjuras de los nobles, en las dudas del monarca y en la ejecución del favorito. Gil y Zárate introduce un argumento secundario que complica más la ya complicada relación entre los personajes: Elvira es hija del condestable y está enamorada en secreto, y correspondida, de don Álvaro de Estúñiga, hijo del conde de Plasencia, otro enemigo de Luna.

Los dos primeros actos tienen lugar en un jardín y en el salón de un palacio en Escalona. De carácter expositivo, revelan el carácter de los diversos personajes y

\footnotetext{
${ }^{28}$ Ibidem, p. 1.

${ }^{29}$ Ibidem, p. 2.

${ }^{30}$ Idem.

${ }^{31}$ Ibidem, p. 3.

${ }^{32}$ Idem.

${ }^{33}$ Ibidem, p. 2. En la batalla de la Higueruela, cerca de Granada, las tropas de Juan II, mandadas por el condestable, vencen a las de Mohamad Nasrid, sultán de Granada en 1431.

${ }^{34}$ Ibidem, p. 3.

${ }^{35}$ Ibidem, p. 2.
} 
la caótica situación política en Castilla. El rey, a solas con el condestable, le pide que abandone la corte para lograr la paz del reino aunque «tu vida es mi vida; que aunque quiera, / no le es dado a tu rey dejar de amarte» ${ }^{36}$. Don Álvaro insiste en permanecer a su lado aunque el rey le previene:

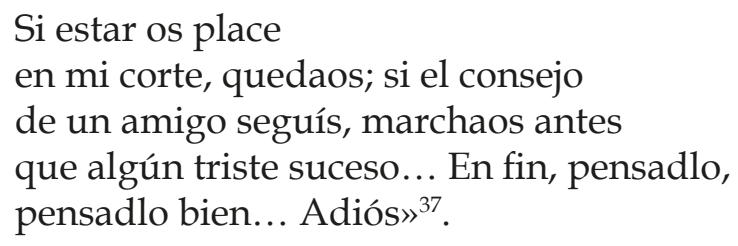

El marqués de Villena don Juan Pacheco, el enemigo más encarnizado del condestable, pretende pactar con él para heredar su poder y su riqueza, mediando el matrimonio con la bella Elvira. Pero ésta le detesta y Pacheco, deseoso de venganza, atrae a su bando a partidarios del condestable, como Alonso Pérez de Vivero, antes su criado de confianza y amigo. Aunque los nobles han recibido mil mercedes de don Álvaro, siguen intrigando contra él, pero éste descubre una conjura y el rey ordena la prisión de Pacheco.

El tercer acto se desarrolla en Burgos. El escenario representa la galería de un palacio, que da a un patio, desde la que se ve una torre. Vivero ha hecho escapar a Pacheco por un pasadizo, y cuando Elvira va a casarse con Estúñiga, Pacheco la hace raptar pero es rescatada por su esposo. El angustiado padre se bate con Pacheco y, cuando éste huye herido, deja caer una escarcela, con cartas que revelan la traición de Vivero. Don Álvaro le hace arrojar desde una torre, y antes de morir, Vivero predice que «mi suplicio / del tuyo causa será» ${ }^{38}$. La luna ilumina la escena.

Cuando Juan II se entera de este asesinato (acto IV), decide, no sin dudarlo mucho, ordenar a Estúñiga que arreste al condestable. Pero en vez de hacerlo, Estúñiga le suplica que huya, Luna no puede creer que el rey olvide sus grandes servicios a lo largo de tantos años y, orgulloso de su honor y de su fama, le entrega su espada: «Al rey, mi señor, todo lo debo:/ su querer es mi ley... Si le acomoda, / cual me pudo elevar, puede abatirme» ${ }^{39}$.

El drama concluye en una gran sala del palacio en el que está preso don Álvaro. Por una «ancha ventana gótica ${ }^{40}$ se ve la plaza mayor de Valladolid. Está acompañado del fiel paje Morales, a quien da una sortija que antaño le había dado el rey, sereno y

\footnotetext{
${ }^{36}$ A. Gil y Zárate, Don Álvaro de Luna, drama en cinco actos, Madrid, Imprenta de Yenes, 1840, p. 20.

${ }^{37}$ Ibidem, p. 21.

${ }^{38}$ Ibidem, p. 72.

${ }^{39}$ Ibidem, p. 88.

${ }^{40}$ Ibidem, p. 91.
} 
dispuesto a morir como buen cristiano:
¿Qué importa la muerte
cuando con gloria se alcanza?
[...] Un día con rectitud
la historia a los dos juzgando,
mi lealtad ensalzando,
culpará su ingratitud ${ }^{41}$.

Sobre la mesa, un reloj de arena marca la fugacidad del tiempo.

Inesperadamente aparece un embozado, que resulta ser el rey. Sigue un diálogo con el preso, en el que ofrece perdonarle pero éste no lo acepta porque «¿a qué quiero un perdón que me condena / a ser del vulgo vil desprecio y burla? / Para el fuerte varón la vida acaba / donde acaba el honor» ${ }^{42}$. La soberbia y el orgullo de Luna irritan al rey: «Húndete en ella [la tumba], pues; y hunde contigo, / ingrato, mi poder y mi ventura» ${ }^{43}$. Pero el tono del rey cambia patéticamente de la acusación al ruego y al recuerdo de su vieja amistad: «¿Ah, qué será de mí si me abandonas?» ${ }^{44}$. Y así acaba la última entrevista que más parecería la tierna despedida de dos amantes.

En la lucha contra el tiempo - recordemos el reloj de arena-Morales llega al fin con el anillo que garantiza el perdón real, Elvira se echa a los pies del rey y consigue el indulto, pero llegan cuando ya suenan las tres en el reloj de la torre. El malvado Pacheco, que asiste embozado a su triunfo, le había hecho adelantar, y por la amplia ventana ven, y también los espectadores del drama, el cadalso y el cadáver de don Álvaro. Elvira da un grito y cae desmayada en brazos de Estúñiga: «¡Cielos! ¡No es tiempo ya! / ¡Jesús mil veces!» ${ }^{45}$.

El rey Juan II es «noble, galán, cortesano, / a par que batallador, / así pulsa harpa sonora, / como vibra su lanzón» ${ }^{46}$ pero más falto de voluntad y más indeciso que en otras versiones literarias, y temeroso de la soledad y el desamparo en que le deja la ausencia del condestable. La imagen de este don Álvaro, «viejo, soberbio y áspero, abusando del largo trato y privanza ${ }^{47}$ como le pinta Quintana, no corresponde a la que tiene de él el rey, pesaroso de su decisión pero incapaz de imponerse.

\footnotetext{
${ }^{41}$ Ibidem, pp. 95-96.

${ }^{42}$ Ibidem, p. 98.

${ }^{43}$ Ibidem, p. 99.

${ }^{44}$ Idem.

${ }^{45}$ Ibidem, p. 169.

${ }^{46}$ Ibidem, p. 3.

${ }^{47}$ M. J. Quintana, ob. cit., p. 214.
} 
En Don Álvaro de Luna se dan los recursos propios de los dramas históricos de la época como son la inverosimilitud y las exageraciones, los personajes embozados, los pasadizos secretos, las cartas reveladoras halladas casualmente, así como los efectos visuales -las dramáticas escenas iluminadas por la luna o por candelabros-y sonoros -las campanadas del reloj que anuncia la muerte del protagonista. Aunque el drama abunda en las convencionales comparsas de ballesteros, cortesanos y criados, y aparecen conocidos políticos y gente de letras de aquel tiempo como el marqués de Villena, el de Santillana y Juan de Mena, no hay mención de la reina, que tan importante papel tuvo, y el de los frailes es muy secundario.

Don Álvaro de Luna, quien al decir de Mata Carriazo, fue «el hombre más poderoso entre los que no ciñeron corona de toda la historia medieval de España» ${ }^{48}$, tuvo en su tiempo tantos panegiristas como detractores. Quienes escribieron después sobre su vida y las circunstancias de su muerte se basaron en las obras de aquellos cronistas que juzgaron al difunto condestable según sus propias simpatías políticas.

No parece fácil deslindar cuáles fueron las fuentes de información de quienes escribieron sobre don Álvaro. Entre las que se mencionan están la Crónica del Cardenal González de Mendoza; la Apología de D. Álvaro de Luna. Parte V de Pedro Salazar de Mendoza; la Crónica de D. Álvaro de Luna de autor anónimo, que Mata Carriazo atribuyó al partidario del condestable Gonzalo Chacón; la Crónica de D. Juan II, año 1453, cap. II, de Fernán Pérez de Guzmán; y el Centón Epistolario, una superchería por Juan Antonio de Vera, conde de la Roca, atribuida al bachiller Fernán Gómez de Ciudarreal. No sé cuán accesibles serían estas obras a quienes escribieron ya terciado el siglo XIX, pero la fuente más cercana sería «Don Álvaro de Luna», la biografía de Quintana, que forma parte de su Vidas de españoles célebres, y que vio la luz en 1833. Y el mismo Quintana cita como fuentes de su obra la

Crónica de Don Juan el Segundo, Crónica de Don Álvaro, Seguro de Tordesillas, Centón Epistolario del bachiller Cibdareal, Generaciones y semblanzas de Fernán Pérez de Guzmán, Historiadel Gran Cardenal de España, Mariana, Zurita y demás compiladores generales. Algunos documentos inéditos del tiempo, comunicados al autor ${ }^{49}$.

Y a estas fuentes se añadirían treinta y cinco romances sobre don Álvaro, uno de ellos de Quevedo, que recogió Agustín Durán en su Romancero.

«The Fate of Luna» de Trueba y Cosío, apareció en 1830 y, según Menéndez Pelayo, la descripción del suplicio del condestable «en algo recuerda la de la admirable

\footnotetext{
${ }^{48}$ J. de Mata Carriazo (ed.), Anónimo, Crónica de Don Álvaro de Luna. Condestable de Castilla, Maestre de Santiago, Madrid, Espasa-Calpe, 1940, p. XI.

${ }^{49}$ M. J. Quintana, ob. cit., p. 371.
} 
carta penúltima, auténtica o apócrifa del Centon Epistolario» ${ }^{50}$. El duque de Rivas también sigue muy de cerca el supuesto relato de Ciudarreal aunque, a mi parecer, el texto de Quintana podría ser su fuente de referencia más cercana, suponiendo que, habiéndose publicado el romance de Rivas y las Vidas de Quintana en el mismo año, hubiese precedido ésta a la redacción del romance. En su drama Don Álvaro de Luna (1840) Antonio Gil y Zárate se aparta voluntariamente de la historia y da paso a la ficción aunque en el texto impreso de su obra indica en ocasiones que algunos de los hechos mencionados son históricos. Y «F. M.», el autor de El Suplicio de D. Álvaro de Luna, con pie de imprenta de 1872, muestra conocer sobradamente el tema.

Los encontrados juicios de panegiristas y detractores han llevado a la historia a Juan II como un rey débil y cobarde, incapaz de gobernar y a merced de quienes se disputaban su influencia. Débil e ingrato le llama Trueba y Cosío, y tanto él como Rivas le muestran temeroso de la dominante doña Isabel su esposa, a quien no osa contradecir; $\mathrm{y}$ «F. M.» hace un retrato de aquel rey, que «para mandar nacido / todos menos él gobiernan ${ }^{51}$. Pero, como ya vimos, la versión más negativa es la de Gil y Zárate, quien le ve como un ser indeciso e ingrato, cobarde, y quizás como un viejo histérico y patético.

Don Álvaro tenía dieciocho años cuando entró al servicio de Juan II, un niño entonces de tres, quien desde tan tierna edad mostró tan gran cariño por su amigo que se entristecía y lloraba cuando no estaba a su lado. Según The Encyclopedia of Homosexuality, citada por Gregory S. Hutcheson, la relación homosexual más famosa de la historia de España fue la de Juan in con su amante Álvaro de Luna, varios años mayor que él (hacia 1390-1454), quienes compartieron un dormitorio muchos años, (aunque según las costumbres de entonces, la de dormir los nobles a los pies del rey era una codiciada marca de favor $)^{52}$. Hutcheson combate esta aserción en su artículo «Desperatly Seeking Sodom: Queerness in the Chronicles of Álvaro de Luna» ${ }^{53}$ basándose en el estudio del tan difundido Memorial de agravios dirigido por los nobles al rey en el que acusaban al condestable de una larga lista de delitos como eran la desordenada codicia, la violencia, la corrupción e indirectamente su homosexualidad, entre otras cosas, y que a pesar de su injurioso carácter de libelo sirvió después de

\footnotetext{
${ }^{50}$ S. García Castañeda, Don Telesforo de Trueba y Cosío, 1799-1835. Su tiempo, su vida y su obra, Santander, Institución Cultural de Cantabria, 1978, p. 251.

${ }^{51}$ F. M., El Suplicio [...], ob. cit., p. 1.

52 «The most famous homophile relationship in Spanish history is that between Juan II and his older lover Álvaro de Luna (ca.1390-1453), who shared a bedroom for years» (Wayne R. Dynes y Stephen Donaldson, eds., The Encyclopedia of Homosexuality, Garland Pub, 1990, p. 640).

${ }^{53}$ G. S. Hutcheson, «Desperately Seeking Sodom: Queerness in the Chronicles of Álvaro de Luna», Josiah Blackmore (ed.), Queer Iberia. Sexualities, Cultures, and Crossings from the Middle Ages to the Renaissance, Durham \& London, Duke University Press, 1999, pp. 222-249.
} 
fuente a muchos historiadores.

Intencionadamente o no, Gil de Zárate destaca la ambigua intimidad del rey con su favorito y el último diálogo entre ambos expresa la congoja y desamparo del rey, y a la vez trae ecos de una querella entre amantes:

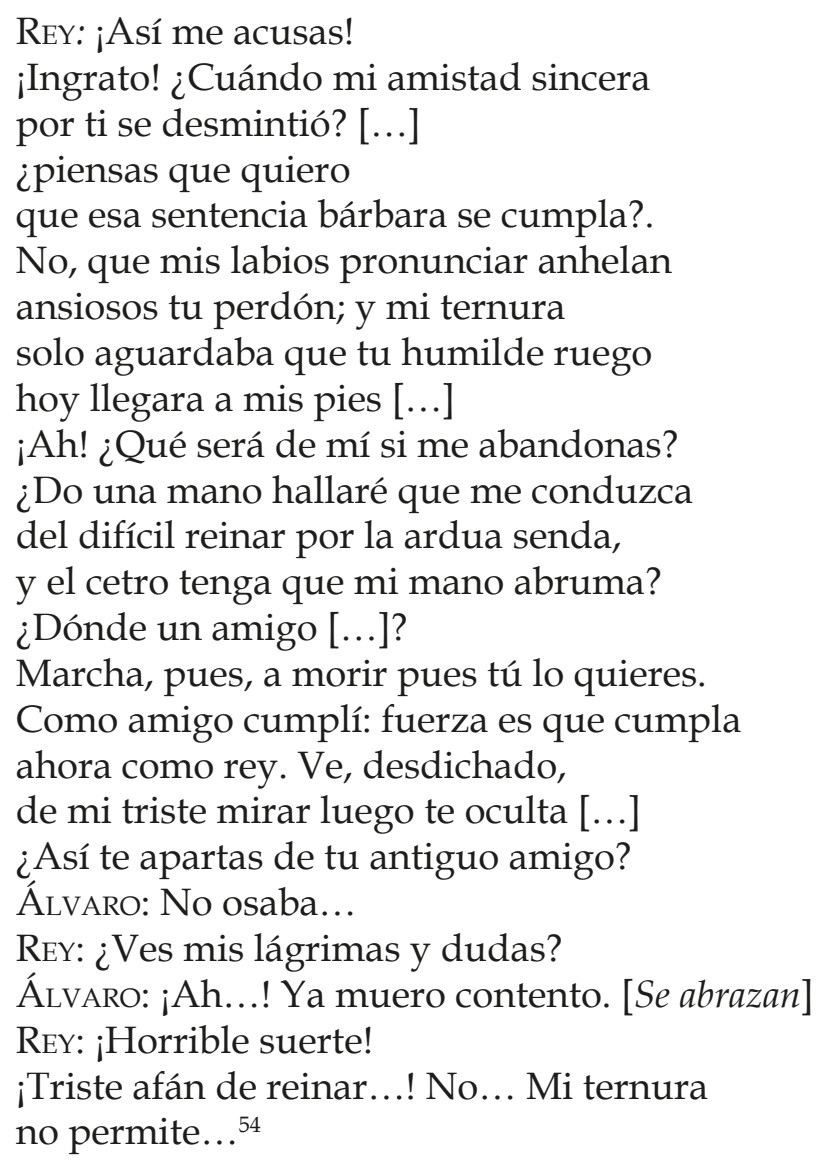

Para su estudio sobre don Álvaro de Luna, Manuel José Quintana tuvo en cuenta diversas fuentes históricas según las cuales Álvaro fue hijo de un caballero ilustre y de una señora que fue lo contrario de honesta y virtuosa; huérfano de temprana edad, fue protegido por su tío el arzobispo de Toledo don Pedro de Luna y por su tío-abuelo el antipapa Benedicto XIII, entró al servicio de palacio y se distinguió muy pronto por su inteligencia y por su ingenio, por su simpatía y por su trato de gentes.

Tanto por su habilidad política como por la protección del rey, gobernó Castilla casi cuarenta años, alcanzó los puestos más altos y acumuló más bienes que todos los grandes hombres de su tiempo. De nuevo según Quintana,

Tendría el condestable cuando sus enemigos le acabaron sobre sesenta y tres años,

\footnotetext{
${ }^{54}$ A. Gil y Zárate, ob. cit., pp. 97-101. En su estudio sobre Enrique Iv, Gregorio Marañón considera a Juan II como un personaje cultivado y sensible, amante de las poesía y de la música pero cuya vida fue «un tejido de abdicaciones, de sensualidades desaforadas y de injusticias» (G. Marañón, Ensayo biológico sobre Enrique IV de Castilla y su tiempo, Buenos Aires, Espasa Calpe Argentina, 1948, p. 29).
} 
y todavía en aquella edad conservaba íntegros el esfuerzo, la agilidad, la viveza y la aplicación por donde se había señalado desde su juventud primera [...]. Mediano de estatura, gracioso y derecho de talle, alcanzaba grandes fuerzas y en todas sus acciones y movimientos mostraba una flexibilidad y soltura que jamás perdió... Vestíase bien, armábase mejor [...] siempre se mostraba gran jinete, gran montero, diestro justador y valentísimo soldado [...] era muy galán y atento con las damas, y fue muy discreto y reservado en sus amores. En hechos de guerra pocos de su tiempo se le pudieron comparar; en sagacidad y penetración política, en tesón y atrevimiento, ninguno le compitió ${ }^{55}$.

Y resumiendo las críticas de sus enemigos, añade:

Pero estas dotes eminentes fueron lastimosamente deslucidas por la ambición de adquirir estados, que no tenía límite alguno, con la codicia de allegar tesoros, todavía más vergonzosa. En fin, con el orgullo indómito, la soberbia y acaso la crueldad inhumana de que se revistió en sus últimos tiempos y le enajenó las voluntades: como si fuera achaque necesario de la privanza excesiva no ejercerse nunca sin arrogancia y sin insolencia ${ }^{56}$.

Las obras examinadas en este trabajo ensalzan al condestable, pero no dejan de mencionar su vanidad, su arrogancia y su afán de mando, ni que el asesinato de López Vivero fuera la causa inmediata de su caída. Para la difusión y popularidad de su historia fue decisiva su lastimosa muerte en el cadalso. El Romanticismo le idealizó como un ser de excepción, de triste destino, y precisamente las circunstancias de su muerte fueron la parte de su biografía que más atrajo a sus panegiristas. Mata Carriazo destacaba que en la Crónica de Don Álvaro de Luna, «Años enteros pasan en silencio y a otros muchos se les despacha con una o dos páginas mientras los episodios de la prisión del condestable, ocurridos en muy pocas horas, se narran con todo detalle y llenan más de 50 páginas» ${ }^{57}$. En «The Fate of Luna» (el título ya destaca su triste destino), Trueba y Cosío se detiene en destacar la gran presencia de ánimo y la dignidad con que el condestable recibió la muerte. El futuro duque de Rivas se ciñe al breve período que va desde la mañana en que los frailes le encuentran en el camino hasta el momento de su ejecución al día siguiente, cuya descripción ocupa el extenso romance III. El pliego de cordel El Suplicio de D. Álvaro de Luna, cuyo título también indica el interés del autor por el triste fin, por el suplicio de aquel, tiene dos partes, con la segunda, bastante más extensa, dedicada a su muerte. Y en el drama de Gil y Zárate el período de tiempo es indefinido pero muy breve. Estas versiones, centradas en la muerte del condestable, que es el episodio más dramático y de más interés para el público lector, destacan la dignidad, la presencia de ánimo, la resignación, el espíritu cristiano y la elegancia con las que fue a la muerte y que le devolvieron la compasión y el respeto del pueblo.

\footnotetext{
${ }_{55}^{5}$ M. J. Quintana, ob. cit., p. 431.

${ }^{56} \mathrm{Idem}$.

${ }^{57}$ J. de Mata Carriazo, ob. cit., p. XII.
} 
Todas tienen carácter hagiográfico por lo que omiten o por lo que no insisten sobre aquellos delitos del protagonista que divulgó en su día el Memorial de agravios, y que repitieron después otros autores. En las obras de carácter literario la creatividad de los autores está limitada por tratar todos un mismo tema al que ofrecen variantes la diversidad de sus fuentes o su propia inventiva. Tanto el duque de Rivas como Trueba y el autor de El Suplicio de D. Álvaro de Luna sustituyen el cuchillo con el que fue degollado el condestable por un hacha; el fiel paje Morales que en estas obras recibe un anillo y, en ocasiones, un sombrero, fue según la Crónica de D. Álvaro de Luna, uno de quienes le traicionaron a última hora. Basándose en las crónicas, Trueba y el duque de Rivas hacen al noble Estúñiga enemigo del condestable mientras que Gil y Zarate le casa con su hija. También cambian ligeramente otros detalles, como las breves palabras del condestable con el verdugo.

Frente a la imagen del mundo caballeresco de aquella idealizada Edad Media de torneos y ceremonias cortesanas, contrasta la realidad del diario vivir de aquellos esforzados caballeros de rutilante arnés y de aquellas bellas princesas, ávidos todos de poder y de fortuna, intrigantes y sin escrúpulos, en un reino de Castilla conflictivo y turbulento. La verdadera historia del desdichado condestable, extremado en sus virtudes y en sus defectos, idealizado por la ejemplaridad de su muerte, ilustraría las legendarias palabras: «Castilla, que hace los hombres y los gasta ${ }^{58}$.

\section{Bibliografía}

Anónimo, Crónica de Don Álvaro de Luna. Condestable de Castilla, Maestre de Santiago. Juan de Mata Carriazo (ed.), Madrid, Espasa-Calpe, 1940.

Dynes, W. R. y S. Donaldson, eds., The Encyclopedia of Homosexuality, Garland Pub, 1990,

F. M., El Suplicio de D. Álvaro de Luna (1453), número 40, Madrid, Depósito Central, Librería de la Viuda e hijos de D. J. Cuesta, Imp. de J. Noguera a cargo de M. Martínez, 1872.

García Castañeda, S., Don Telesforo de Trueba y Cosío, 1799-1835. Su tiempo, su vida y su obra, Santander, Institución Cultural de Cantabria, 1978.

Gil y ZÁrAte, A., Don Álvaro de Luna, drama en cinco actos, Madrid, Imprenta de Yenes, 1840.

HutchesON, G. S., «Desperately Seeking Sodom: Queerness in the Chronicles of Álvaro de Luna», Josiah Blackmore (ed.), Queer Iberia. Sexualities, Cultures, and Crossings

\footnotetext{
${ }^{58}$ Pronunciadas por Don Alfonso Fernández Coronel antes de ser degollado y quemado por orden del rey don Pedro I de Castilla.
} 
from the Middle Ages to the Renaissance, Durham \& London, Duke University Press, 1999, pp. 222-249.

Marañon, G., Ensayo biológico sobre Enrique IV de Castilla y su tiempo, Buenos Aires, Espasa Calpe Argentina, 1948.

Mata Carriazo, J. de (ed.), Anónimo, Crónica de Don Álvaro de Luna. Condestable de Castilla, Maestre de Santiago, Madrid, Espasa-Calpe, 1940.

QuintAnA, M. J., «Don Álvaro de Luna», en Vidas de españoles célebres, Madrid, Biblioteca de Autores Españoles, XIX, Imprenta y Estereotipia de M. Rivadeneyra, 1852, pp. 367-431 y pp. 502-504.

SAAvedra, Á., duque de Rivas, Romances históricos, Cipriano Rivas Cherif (ed.), Madrid, Clásicos Castellanos, Ediciones La Lectura, 1911, 2 vols.

, Romances históricos, Salvador García Castañeda (ed.), Madrid, Cátedra, 1987.

,El paso honroso. Obras completas, I, Poesías, Jorge Campos (ed.), Madrid, Biblioteca de Autores Españoles, 1957, pp. 66-94.

Trueba y Cosío, T., «The Fate of Luna», The Romance of History. Spain. With Illustrations by J. K. Meadows, The Chandon Classics, London, Frederick Warne and Co., 1872, pp. 401-425. $1^{\mathrm{a}}$ ed.: The Romance of History. Spain, III, Londres, Edward Bull, propietario de la New Subscription Library, 1830. 